\title{
An examination of prefrontal lesion size and the effects of cortical grafts on performance of the Morris water task by rats
}

\author{
BRYAN D. FANTIE and BRYAN KOLB \\ University of Lethbridge, Lethbridge, Alberta, Canada
}

\begin{abstract}
We studied the effects of prefrontal cortex lesions and prefrontal cortical grafts on the performance of rats in the Morris water task. Adult male rats received cortical tissue grafts (E21) 2 weeks after aspiration of the medial prefrontal cortex. They were later studied in the Morris water maze, and their behavior was subsequently correlated with lesion size, graft presence, and graft size. The results showed that lesion size had a major effect on behavior: animals with lesions including the prelimbic cortex were unable to learn the location of the hidden platform, whereas those with lesions sparing this cortex eventually learned the task, although they were impaired relative to control animals. The presence of cortical grafts had no chronic effect upon behavior, and the size of the graft also did not predict behavior. True Blue injections into the host or graft in different animals showed that although the grafts invaded the hosts, the hosts did not invade the grafts themselves. These results are consistent with the growing body of evidence that suggests that cortical grafts do not allow the re-establishment of neural networks that replace the lost tissue, although there may be a general trophic effect of cortical grafts.
\end{abstract}

It has been almost a century since it was discovered that small, central nervous system tissue grafts can survive and make connections in a host (Dunn, 1917; LeGros Clark, 1940; May, 1930; Thompson, 1890). Only relatively recently, however, has this technique begun to be systematically investigated as a means of facilitating behavioral recovery after brain damage which, in an adult of the higher mammals, was once thought to be completely irreversible. Thus, neural transplantation is reported to improve a variety of behavioral aberrations produced by lesions. These include diurnal behavioral rhythmicity (Drucker-Colin, Aguilar-Roblero, GarcíaHernández, Fernández-Canciono, \& Rattoni, 1984), lesioninduced rotation (Freed, 1983), locomotor hyperactivity, stereotypy (Deckel, Moran, Coyle, Sanburg, \& Robinson, 1986), maze learning (Kimble, Bremiller, \& Stickrod, 1986), sexual behavior (Luine, Renner, Frankfurt, \& Azmitia, 1984), and brightness discrimination (Stein, Labbe, Attella, \& Rakowsky, 1985).

The possibility that functional loss following neocortical injury might be reduced by cortical grafts was given credance by Labbe, Firl, Mufson, and Stein (1983). They reported that embryonic cortical tissue transplants can par-

This research was supported by a grant from the Medical Research Council of Canada to B.K. B.D.F. is an Alberta Heritage Foundation for Medical Research Postdoctoral Fellow, and is currently at the American University, Washington, DC. Reprint requests may be addressed to Bryan Kolb, Department of Psychology, University of Lethbridge, Lethbridge, Alberta T1K 3M4, Canada.

-Accepted by previous editor, Lynn Nadel tially ameliorate the cognitive deficits associated with successfully performing a spatial alternation task in a $T$ maze by rats with medial frontal cortex lesions. Subsequent studies of the effects of frontal cortical grafts have been less promising, however. For example, Dunnett, Ryan, Levin, Reynolds, and Bunch (1987) found that tissue taken from E21 donors produced a short-lasting improvement in the T-maze task but was without benefit in the Morris water task. Similarly, Kolb, Reynolds, and Fantie (1988) and Fantie and Kolb (1985) found that frontal cortical grafts could produce either a short-lasting improvement, or could actually worsen the impairments of frontal rats in the Morris water task. A significant difference between the Labbe et al. results and the later studies is that the frontal lesions were significantly smaller in the former experiments, as they spared the prelimbic and infralimbic regions of the prefrontal cortex, whereas the latter studies included this tissue. This difference could be important since, in the case of smaller lesions, the grafts would actually be attaching to prefrontal tissue, whereas with larger lesions the grafts would be connecting with the motor cortex or, in some cases, with the olfactory bulb or tract. The present experiment was conducted to reexamine the water-maze results by manipulating lesion size. The experiment also allowed us to determine if lesion size affects water-maze performance independent of grafts. The importance of the Morris water task in investigating prefrontal cortex function is that, in contrast to tests such as $\mathrm{T}$-maze alternation, rats with large lesions do not acquire the water-maze task, even with extended training (e.g., see Kolb, Pittman, Sutherland, \& Whishaw, 1982; Sutherland, Kolb, \& Whishaw, 1982). 


\section{METHOD}

\section{Subjects}

All animals used in this project were obtained from Canada Breeding Farms and weighed $250-350 \mathrm{~g}$ at the time of surgery. The rats were housed in stainless steel hanging cages kept in a temperaturecontrolled colony room maintained on a 12:12 h light:dark cycle. Testing took place during the diurnal period. Purina Lab Chow and tap water were available ad lib in the home cages.

\section{Surgery}

Under sodium pentobarbital anaesthesia (Somnotol, $65 \mathrm{mg} / \mathrm{kg}$ i.p.), 44 adult male Long-Evans rats had their medial frontal cortex removed by aspiration. One group (lesion + transplantor, $\mathrm{MF}+\mathrm{G}, n=25$ ) received grafts of cortical tissue taken from E21-22 rats 8-25 days later. During this same period, the other group (MF, $n=19$ ) was reanaesthetized, had their scalp incisions opened and then resutured. A third group (CONT, $n=10$ ) served as unoperated controls. Most of the previous research that has reported improved behavioral recovery in animals with brain damage following neural tissue transplants used younger fetal donor tissue. In contrast to these studies, we used grafts taken from E21-22 brains because this was the age chosen by Labbe et al. (1983). One advantage of choosing tissue of this age is that the graft tissue should have a complete complement of neuronal elements, whereas younger tissue, obtained at E19 or earlier, would be taken before the migrating cells that form Layers II and III had reached the frontal cortex (Hicks \& D'Amato, 1968).

Flourescent tracing. To determine if the grafts and host brains were interacting, we injected 8 of the grafted rats with flourescent tracers into either the graft $(n=4)$ or the host $(n=4)$ as soon as behavioral testing was complete. The injections into the graft were $0.1 \mu \mathrm{l}$ of $5 \%$ True Blue, which was delivered by placing a $1-\mu l$ syringe into the graft under visual guidance. The injections into the host brains were made by making two different injections into the host, located about $2 \mathrm{~mm}$ from the host-graft border and separated in an anterior/posterior extent by $2-4 \mathrm{~mm}$, depending upon the graft size. The animals were allowed 7 days of recovery before sacrifice.

Histological processing. After completion of the experiments, the rats were sacrificed with an overdose of sodium pentobarbital and perfused with $0.9 \%$ saline followed by $10 \%$ formalin. The brains were weighed and about half were processed for embedding in celloidin and sectioned at $25 \mu \mathrm{m}$. For the other half, which included the brains with True Blue injections, the brains were placed in $30 \%$ sucrose formalin and cut frozen in $40-\mu \mathrm{m}$ sections. Every fifth section was mounted and stained with cresyl violet. For the rats with True Blue injections, adjacent sections were also kept and mounted separately for flourescent viewing

\section{Behavioral Tests}

Morris water maze. The entire inside surface of a circular pool (85-cm diam., 45-cm high) was painted white and filled with water (kept at approximately $18^{\circ} \mathrm{C}$ ) to a height of $25 \mathrm{~cm}$ in which $1,500 \mathrm{ml}$ of instant powdered skim milk had been dissolved. A white Plexiglas platform $(11 \times 12 \mathrm{~cm})$, was present inside the pool; its top surface was $14 \mathrm{~mm}$ below the surface of the water, making it invisible to a viewer (the rat) inside the pool.

A trial consisted of manually placing a rat into the water so that it was facing and adjacent to the wall of the pool at one of four starting locations corresponding to the cardinal compass points. Within a block of four trials, the rat started at each of the starting locations. The sequence of initial locations was selected pseudorandomly. Behavioral testing was conducted on 5 consecutive days, with each rat receiving eight trials (two trial blocks) on each day. During the first nine trial blocks, the platform was located in the center of one quadrant of the pool. For the final trial block, the platform was moved to the center of the diagonally opposite quadrant. On each trial, we measured the latency to find the platform (maximum $90 \mathrm{sec}$ ) and the magnitude of the initial heading error after swimming approximately one body length $(14 \mathrm{~cm})$. The rat's swim path was recorded automatically by a customized computerized video-tracking system.

\section{RESULTS}

\section{Histology}

All of the lesions were confined to the medial frontal region, but the lesions varied with respect to the presence or absence of damage to the prelimbic and infralimbic regions. The brains were therefore categorized into two groups, namely, small and large lesions. Microscopic inspection of the brains revealed that lesion cavities in the grafted rats were filled with neuronal tissue as well as necrotic tissue, largely composed of glial cells (see Figure 1). There was considerable variance in the size of the graft; the graft filled the entire cavity in some animals, although most grafts were somewht smaller. The neurons in the grafts did not form the laminar structure characteristic of normal cortical tissue but, individually, were similar in appearance to neurons usually found in the frontal cortex, including both stellate and pyramidal cells. Grafts were classified as either small or large. Small grafts appeared as disconnected bits and/or larger chunks of implanted tissue that were situated mostly unilaterally. Large grafts were much more extensive, often completely filling the cavity, and extended bilaterally to occupy sites in both hemispheres. All histological classifications were made without knowledge of the behavioral results.

\section{Retrograde Tracing}

Injections of the tracer were difficult to make into the graft without allowing any leakage of tracer into the CSF. Nonetheless, two of the four injections into the graft appeared to be restricted to the graft, and there was no evidence of leakage into the CSF, such as label lining the ventricular walls. In both of these cases, there was good transport within the graft itself, which implies that there were intragraft connections spanning several millimeters, but there was no evidence of any transport out of the graft and into the host brain. The injections into the host brains were made rather close to the graft border, and 2 of the animals appeared to have had some direct spread of label into the graft. The other two injections were good, however, and these cases showed extensive labeling in the graft (Figure 2). Significantly, the transported label was not found only at the graft-host border; it originated from more distal regions of the graft as well (Figure 2). In summary, the flourescent tracing results indicate that the host brains did not invade the graft tissue but the grafts did invade the hosts.

\section{Behavior}

When initially placed in the tank, the normal control rats traversed a wide area until they bumped into the hidden platform. Performance improved rapidly on succes- 


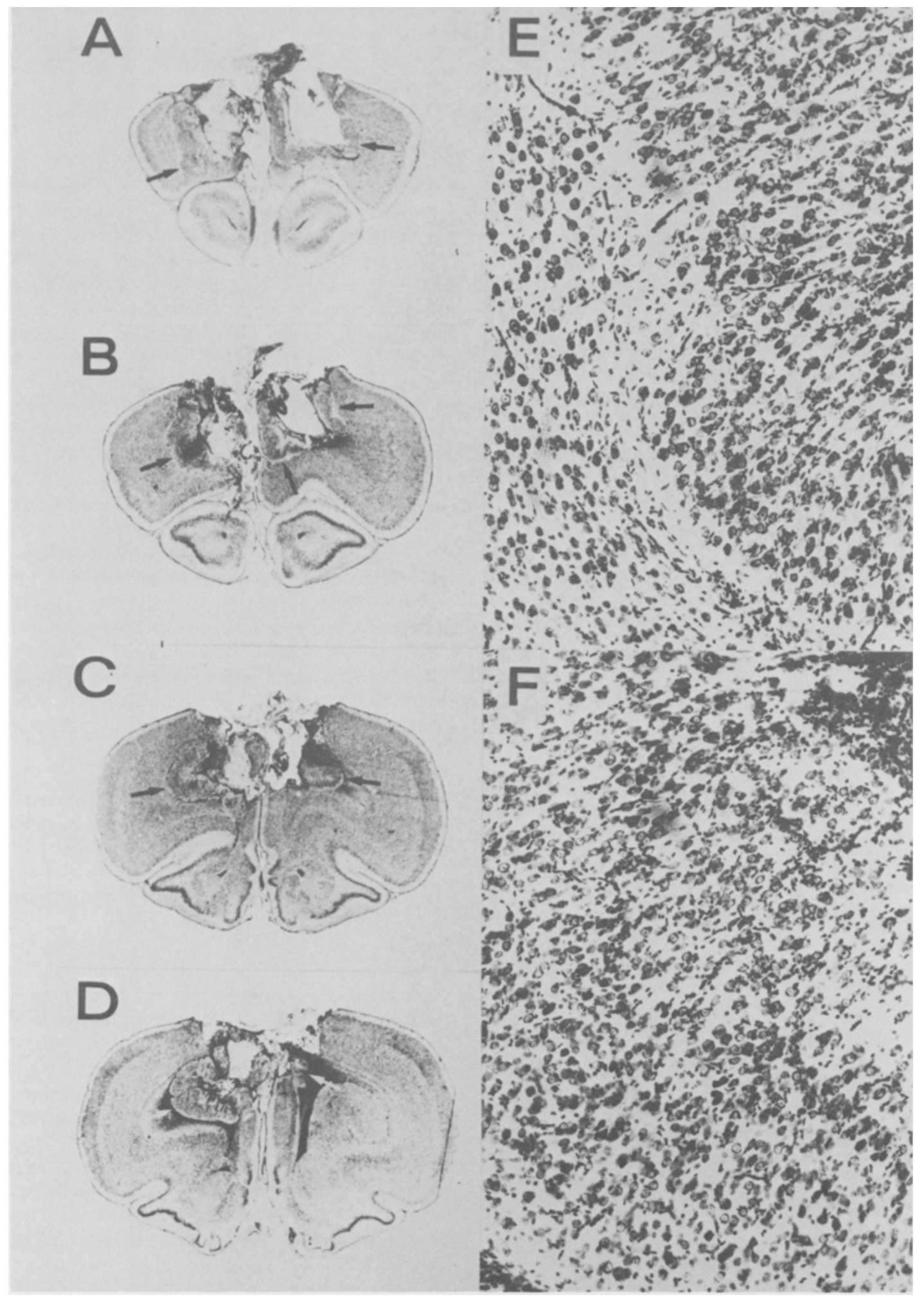

Figure 1. (A-D) Serial sections through a brain with a medial frontal lesion and a graft in each hemisphere. The grafted tissue adjoins the host on both sides and runs continuously along the entire extent of the lesion cavity. (E) Higher magnification view $(250 \times)$ of the host-graft border from (A). (F) Higher magnification view $(250 \times)$ of the graft from (D). The host-graft border is at the bottom left corner. 


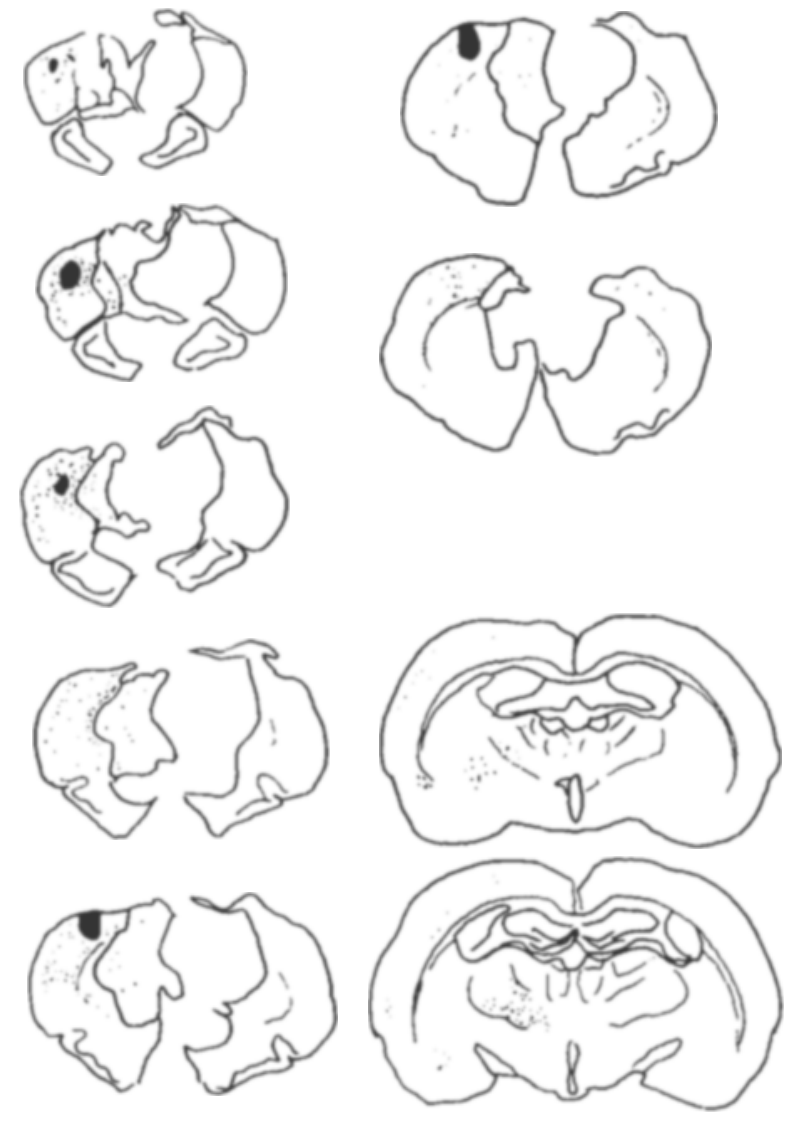

Figure 2. Ilustration of the retrogradely labeled cells following two True Blue injections into the host brain. There is label visible in most sections containing a graft.

sive trials until it reached asymptote at about $5 \mathrm{sec}$ on about the fifth trial block. Analysis of the animals' angle of trajectory from the start location shows considerably more variance than do measures of latency, but by Trial Block 9, the animals' angle of trajectory from the start location to the platform had reduced from chance $\left(39^{\circ}\right)$ to less than $20^{\circ}$. As reported previously (Kolb, Sutherland, \& Whishaw, 1983), animals with medial frontal lesions are impaired in the acquisition of this task and never perform as accurately as control animals. It can be seen in Figure 3 that escape latencies for the lesioned rats over the 10 trial blocks were about four times worse than those for control animals. Furthermore, grafts were without effect, as the rats with and without grafts performed equally poorly. Analysis of variance on total latency was significant $[F(2,48)=5.2, p<.01]$, and follow-up tests (Tukey's $a, p<.01$ ) showed that both the MF and the $\mathrm{MF}+\mathrm{G}$ groups differed from controls but not from one another.

Good performance on the latency measure can be achieved by locating the platform and swimming directly to it, or by learning an effective strategy to find the platform, independent of location, such as swimming a fixed distance from the pool wall. Spatial knowledge can be as- sessed by two measures: performance on the reversal trial and heading trajectory at the beginning of the swim. Normal control animals usually show a large reversal effect as the animals hunt for the platform in the normally correct location for some time before searching elsewhere in the tank. Thus, in the current experiment, the escape latency for the normal control animals increased from 4 to $25 \mathrm{sec}$ between Trial Blocks 9 and $10(t=17.9$, $p<.002$ ). Animals with frontal lesions usually do not show a reversal effect in their latency, and in the current experiment neither the MF nor the MF $+\mathrm{G}$ groups showed a reversal effect; the MF rats had means of 25 and $25 \mathrm{sec}$ on Blocks 9 and $10(t=.079, p>.10)$, and the MF +G rats had means of 23 and $27 \mathrm{sec}$, respectively $(t=.656$, $p>.10$ ). Thus, neither group with lesions appeared to be affected by the reversals, which suggests that they did not know the location of the platform. A similar conclusion can be drawn from the heading angles. Analysis of variance on the heading angle on Block 9 showed a significant effect $[F(2,48)=3.55, p=.04]$. Follow-up tests $(p<.05)$ showed that the control and MF groups differed, but the $M F+G$ group failed to differ from either the control or the MF group.

These same data were reanalyzed after subdividing all of the animals with lesions into two groups: those with
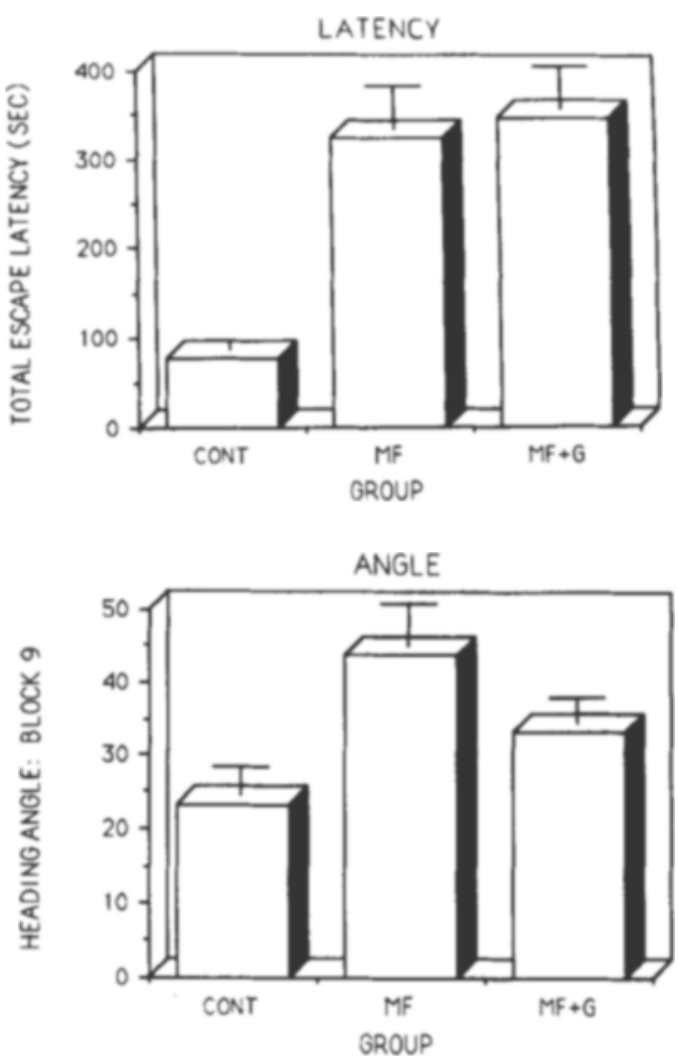

Figure 3. Top: Summary of total escape latency over the first nine trial blocks ( 36 trials). Bottom: Summary of the heading angle on Trial Block 9. CONT $=$ control group, $M F=$ medial frontal lesion group, $\mathbf{M F}+\mathbf{G}=$ medial frontal lesion plus graft group. 

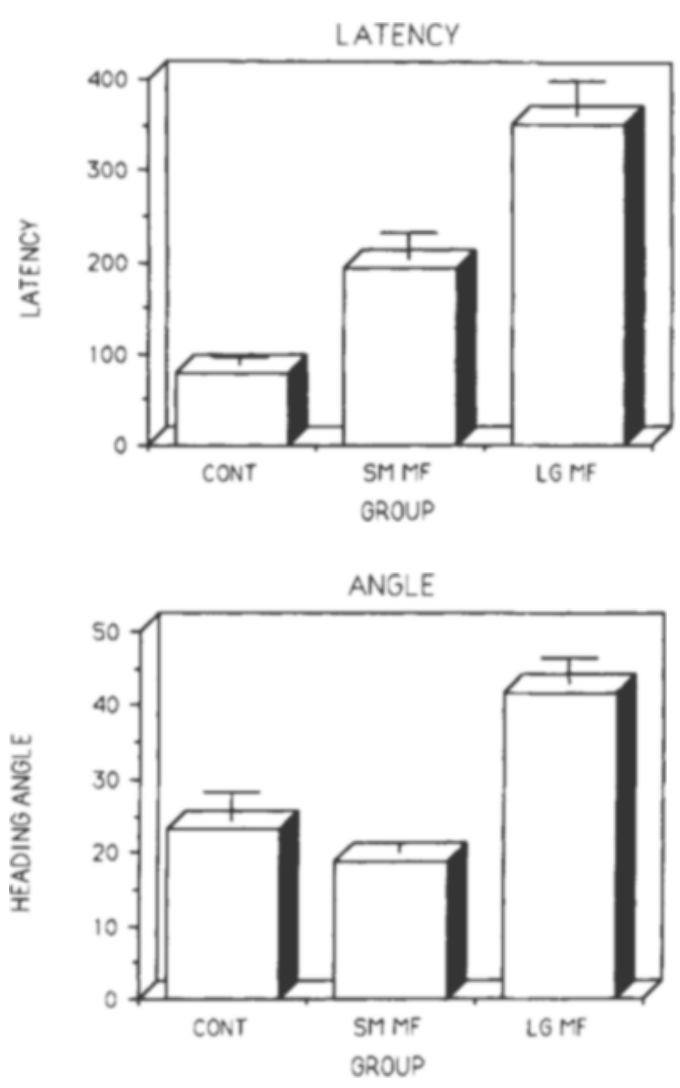

Figure 4. Top: Summary of total escape latency over the first nine trial blocks for control (CONT) rats and rats with medial frontal lesions that either spared the prelimbic cortex (SM MF) or included the prelimbic cortex (LG MF). Bottom: Heading angles on Trial Block 9.

prelimbic and infralimbic damage (LG MF) and those without this damage (SM MF). Figure 4 summarizes these results and shows that lesion size had a striking effect on water-task performance: the animals with small lesions had a deficit in total escape latency but they were far better than those with large lesions, and by Block 9 they had heading angles that were as accurate as those of control animals. Analysis of variance on both latency and heading angle were significant $[F(2,48)=7.27$, $p<.01$, and $F(2,48)=6.07, p<.01$, respectively]. Follow-up tests on the latency showed that all group comparisons were significant $(p<.05)$, whereas similar tests on the Trial Block 9 heading angles showed that both the control and the SM MF animals differed from the LG MF animals $(p<.05)$, but not from each other $(p>.05)$. These results show, therefore, that if medial frontal lesions spare the infralimbic and prelimbic cortex, rats show an initial deficit but are able to acquire the task and eventually swim as accurately as controls to the platform. The possibility that the animals with small lesions learned the platform location is confirmed by considering the reversal data: their latencies increased from 4 to $14 \mathrm{sec}$, which was significant $(t=9.7, p<.01)$.
Finally, the data for the animals with grafts were reanalyzed again by dividing the animals according to the size of the grafts. As can be seen in Figure 5, graft size did not affect water-task performance, whether it was measured by latency or by heading angle $(F \mathrm{~s}<1)$. Thus, graft size did not influence water-task performance. Graft size also did not interact with lesion size $(F<1)$, which again suggests that frontal grafts have little impact upon behavior in the Morris task.

\section{DISCUSSION}

There are three basic findings from this experiment. First, our results confirm previous studies showing little long-term benefit of frontal cortical grafts on the performance of the Morris water task (Dunnett et al., 1987; Fantie \& Kolb, 1985; Kolb et al., 1988). This result stands in contrast to the results of Labbe et al. (1983), who found an improvement in T-maze alternation performance after frontal cortex grafts, a result confirmed by Dunnett et al. (1987) as well as by our laboratory (Fantie, Reynolds, Di Lullo, Anchan, \& Kolb, 1987). The deficit on the Morris water task differs from that on T-maze alternation in that, even with extended training, cortical lesioned animals do not perform the Morris task as well
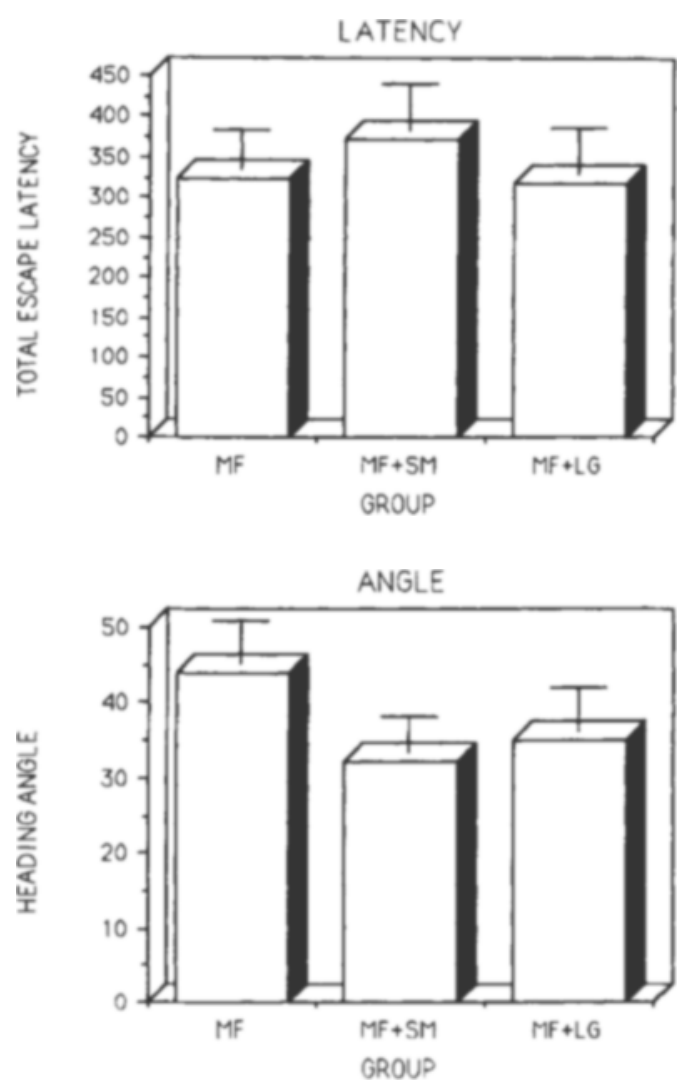

Figure 5. Top: Total escape latency over the first nine trial blocks in rats with medial frontal lesions (MF), or medial frontal lesions with small (MF + SM) or large grafts (MF + LG). Bottom: Heading angle on Trial Block 9 for the same rats. 
as normal control animals, whereas such animals do acquire the T-maze task. The Morris task results do not preclude the possibility that frontal cortex grafts afford some behavioral benefit, but they do leave the mechanism open to question. It has become apparent in recent years that apparent behavioral recovery after cortical grafts could result from (1) direct interaction between the host and graft, (2) a chronic diffuse release of neurochemicals, or (3) some nonspecific effects of the graft (e.g., see Dunnett, 1990). Although the first conclusion originally seemed attractive, the results from several laboratories suggest that cortical grafts may potentiate recovery by means of some nonspecific effect (Dunnett et al., 1987; Kesslak, Nieto-Sampedro, Globus, \& Cotman, 1986; Kolb et al., 1988). It remains unclear why a nonspecific effect would benefit T-maze performance but not water-task performance, although we have shown that there is a transient improvement in water-task performance if the animals are tested immediately after the graft procedure (Kolb et al., 1988).

Our second finding is that although the grafts invaded the host tissue, these connections were not reciprocated. This result appears to be inconsistent with both the findings of Labbe et al. (1983), who found mediodorsal (MD) thalamic-labeled neurons after HRP injections into the grafts, as well as those of Dunnett et al. (1987), who found labeled neurons in the centrolateral thalamus (but not in the MD) and in the globus pallidus, substantia nigra, and locus coeruleus. One difference between the Dunnett et al. study and the present one is that the donor tissue was younger in the Dunnett et al. study. Although it is not clear why this would be important, we have replicated the Dunnett et al. result with injections into grafts that developed from E17 tissue (Kolb \& Fantie, unpublished observations). Perhaps there is some trophic factor in the younger tissue that encourages the host to sprout connections directed into the graft. It is more difficult to determine the difference between the Labbe et al. study and the current one, however, since our grafts were similar in age to the Labbe et al. tissue. One possible reason for the discrepancy might be that Labbe et al. allowed some leakage of tracer into the CSF, and the tracer may have been picked up by thalamostriatal neurons. Another possibility is that the size or placement of the injection may be crucial.

Finally, our results show that lesion size, independent of cortical graft, has a clear effect upon performance in the Morris water task. This result is noteworthy for at least two reasons. First, the magnitude of the deficit in the Morris water task after prefrontal lesions varies considerably from study to study in the literature. Indeed, in our own experiments, we have been impressed by the contrast between the variance in deficit after prefrontal lesions and the relative invariance after hippocampal lesions (e.g., see Kolb, 1987; Kolb et al., 1983; Sutherland et al., 1982). A likely explanation for these differences is that the larger deficits are associated with damage to the infralimbic cortex, which has direct connections with the hippocampus (e.g., see Swanson, 1981). Second, although there are clear differences in both afferent and efferent connections of the prelimbic, infralimbic, and anterior cingulate regions in the rat, there is virtually no evidence regarding the functional importance of these differences (e.g., see Kolb, 1984). The current data suggest that the limbic regions may play a role in spatial navigation that is not shared by the overlying anterior cingulate regions.

\section{REFERENCES}

Deckel, A. W., Moran, T. H., Coyle, J. T., Sanburg, P. R., \& RoBINSON, R. G. (1986). Anatomical predictors of behavioral recovery following fetal striatal transplants. Brain Research, 365, 249-258.

Drucker-Colin, R., Aguilar-Roblero, R., Garcí-Hernández, F., Ferníndez-Canciono, F., \& RAtToni, F. B. (1984). Fetal supraciasmatic nucleus transplants: Diumal thythm recovery of lesioned rats. Brain Research, 311, 353-357.

DunN, E. (1917). Primary and secondary findings in series of attempts to transplant cerebral cortex in the albino rat. Journal of Comparative Neurology, 27, 565-582.

DunnetT, S. B. (1990). Cortical grafts. In B. Kolb \& R. Tees (Eds.), The cerebral cortex of the rat (pp. 589-612). Cambridge, MA: MIT Press.

Dunnett, S. B., Ryan, C. N., Levin, P. D., Reynolds, M., \& BuNCH, S. T. (1987). Functional consequences of embryonic neocortex transplanted to rats with prefrontal cortex lesions. Behavioral Neuroscience, 101, 489-503.

FANTIE, B. D. , KOLB, B. (1985). Cortical grafts impair spatial learning in adult rats with medial frontal cortex lesions. Society for Neuroscience Abstracts, 11, 616.

Fantie, B. D., Reynolds, B., Di Lullo, D., Anchan, R., Kola, B. (1987). Some factors affecting the influence of cortical grafts on the behavioral recovery of rats with medial frontal cortex lesions. Society for Neuroscience Abstracts, 13, 163.

FreED, W. J. (1983). Functional brain tissue transplantation: Reversal of lesion-induced rotation by intraventricular substantia nigra and adrenal medulla grafts, with a note on intracranial retinal grafts. Biological Psychiatry, 18, 1205-1267.

Hicks, S. P., \& D'Amato, C. J. (1968). Cell migrations to the isocortex in the rat. Anatomical Record, 160, 619-633.

Kesslak, J. P., Nieto-Sampedro, M., Globus, J., Cotman, C. W. (1986). Transplants of purified astrocytes promote behavioral recovery after frontal cortex ablation. Experimental Neurology, 92, 377-390.

Kimble, D. P., Bremiller, R., \& Stickrod, G. (1986). Fetal brain implants improve maze performance in hippocampal-lesioned rats. Brain Research, 363, 358-363.

Kolb, B. (1984). Functions of the frontal cortex of the rat: A comparative review. Brain Research Reviews, 8, 65-98.

KolB, B. (1987). Recovery from early cortical lesions in rats: 1. Differential behavioral and anatomical effects of frontal lesions at different ages of neural maturation. Behavioural Brain Research, 25, 205-220.

Kolb, B., Pittman, K., Sutherland, R. J., \& Whishaw, I. Q. (1982). Dissociation of the contributions of the prefrontal cortex and dorsomedial thalamic nucleus to spatially guided behavior in the rat. $B e$ havioural Brain Research, 6, 365-378.

Kolb, B., ReYnoldS, B., \& Fantie, B. D. (1988). Frontal cortex grafts have opposite effects at different postoperative recovery times. $B e$ havioral \& Neural Biology, 50, 193-206.

Kolb, B., Sutherland, R. J., \& Whishaw, I Q. (1983). A comparison of the contributions of the frontal and parietal association cortex to spatial localization in rats. Behavioral Neuroscience, 97, 13-27.

Labbe, R., Firl, A., JR., Mufson, E. J., \& Stein, D. G. (1983). Fetal brain transplants: Reduction of cognitive deficits in rats with frontal cortex lesions. Science, 221, 470-472. 
LeGros Clark, W. E. (1940). Neuronal differentiation in implanted fetal cortical tissue. Journal of Neurology, Neurosurgery \& Psychiatry, 3, 263-272

Luine, V. N., Renner, K. J., Frankfurt, M., \& Azmitia, E. C. (1984). Facilitated sexual behavior reversed and serotonin restored by raphe nuclei transplanted into denervated hypothalamus. Science, 226, 1436-1439.

MAY, R. M. (1930). La greffe dans l'oeil de rat blanc adult du tissu cérébral de rat nouveaune. Archives d'Anatomie Microscopique, 26 , 433-445.

Stein, D. G., Labbe, R., Atrella, M. J., \& Rakowsky, H. A. (1985). Fetal brain tissue transplants reduce visual deficits in adult rats with bilateral lesions of the occipital cortex. Behavioral \& Neural Biol ogy, 44, 266-277.

SUTHERLAND, R. J., KolB, B., \& WhISHAW, I. Q. (1982). Spatial mapping: Definitive disruption by hippocampal or medial frontal cortical damage in the rat. Neuroscience Letters, 31, 271-276.

Swanson, L. W. (1981). A direct projection from Ammon's horn to prefrontal cortex in the rat. Brain Research, 217, 150-154.

Thompson, W. G. (1890). Successful brain grafting. New York Medical Journal, 51, 701-702.

(Manuscript received November 18, 1987; revision accepted for publication November 22,1989 .)

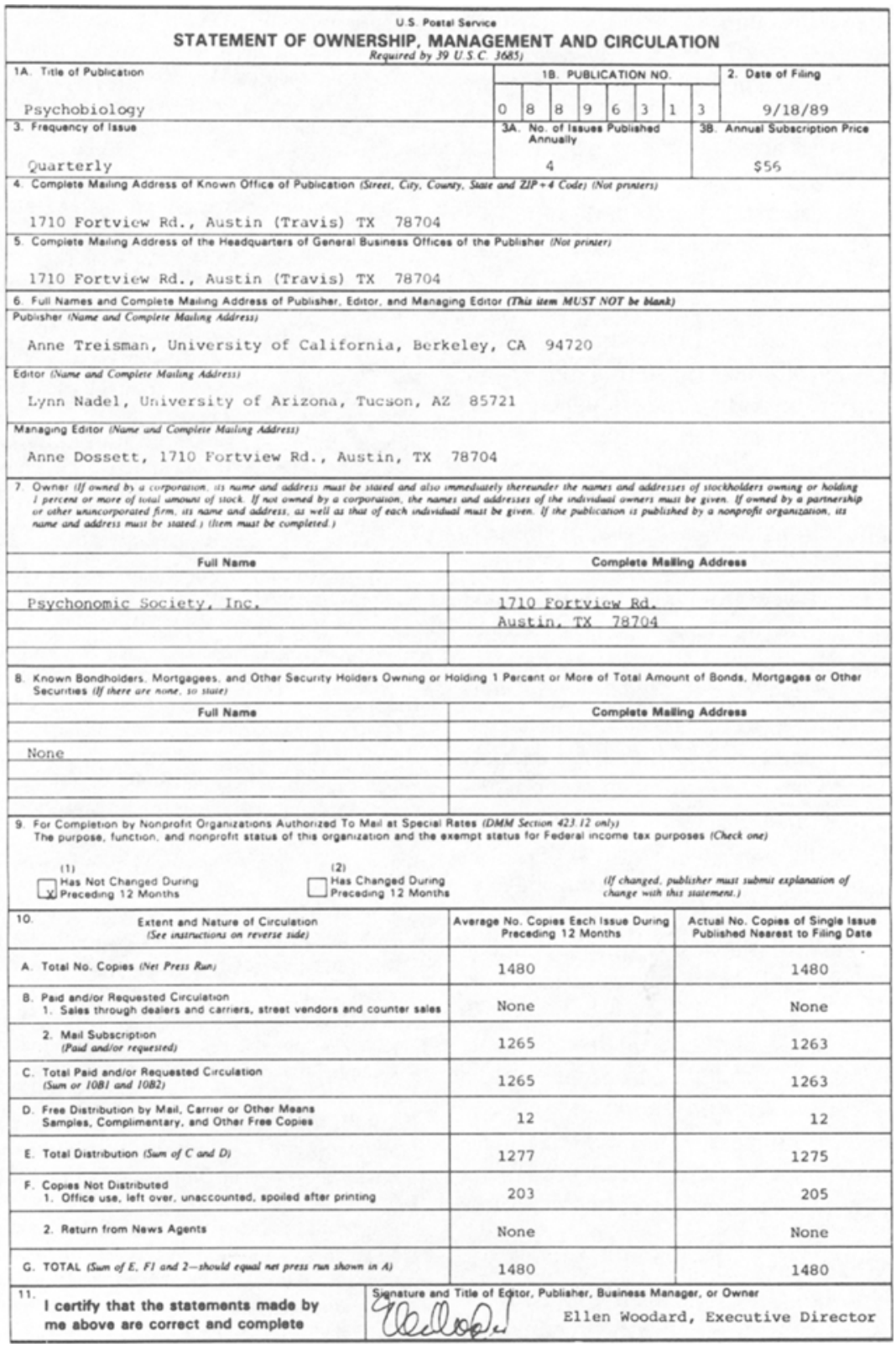

